\title{
Large Basilar Apex Aneurysms Treated with Flow-Diverter Stents
}

\author{
(D) V. Da Ros, (D). Caroff, (D)A. Rouchaud, (D). Mihalea, (D). Ikka, (D). Moret, and (D). Spelle
}

\begin{abstract}
BACKGROUND AND PURPOSE: The treatment of wide-neck, large basilar apex aneurysms is challenging with either an endovascular or a surgical approach. The aim of the present study was to report our experience treating basilar apex aneurysms with flow-diverter stents and to evaluate their efficacy and safety profile in this specific anatomic condition.
\end{abstract}

MATERIALS AND METHODS: We retrospectively analyzed data from all consecutive patients treated with flow-diverter stents at our institution between January 2011 and January 2015. Patients with large basilar apex aneurysms treated with a flow-diverter stent were included in the study. Clinical presentations, technical details, intra- and perioperative complications, and clinical and angiographic outcomes were recorded, with a midterm follow-up.

RESULTS: Of the 175 aneurysms treated with flow-diverter stents at our institution, 5 patients ( 2 women and 3 men; age range, 44-58 years) received flow-diverter stent for basilar apex aneurysms. The mean follow-up after stent deployment was 21 months (range, 15-24 months). One patient died on day 31 from an early postprocedural midbrain hemorrhage. One patient had a right cerebellar hemispheric ischemic lesion with a transient cerebellar syndrome resolved within 24 hours without neurologic sequelae at the latest follow-up. The mRS was 0 in 4 patients and 6 in 1 patient at last follow-up.

CONCLUSIONS: Flow diversion is a feasible technique with an efficacy demonstrated at a midterm follow-up, especially in the case of basilar apex aneurysm recurrences after previous endovascular treatments. Concern about its safety profile still exists.

ABBREVIATIONS: BAA = basilar apex aneurysm; $\mathrm{mRR}=$ modified Raymond-Roy; $\mathrm{PCA}=$ posterior cerebral artery

W ide-neck, large basilar apex aneurysms (BAA) are rare lesions that account for approximately $7 \%-8 \%$ of all intracranial aneurysms. ${ }^{1,2}$ Their treatment is challenging when using either endovascular or surgical approaches. ${ }^{3,4}$

The endovascular approach is considered the "gold standard" for posterior circulation intracranial aneurysms because of a lower rate of procedural complications compared with surgery. ${ }^{5}$ However, long-term angiographic studies of large posterior circulation aneurysms after coiling show high recurrence rates. ${ }^{6}$

The advent of flow-diverter stents has allowed for the treat-

Received December 6, 2016; accepted after revision January 31, 2017.

From the Department of Diagnostic Imaging and Interventional Radiology, Molecular Imaging and Radiotherapy (V.D.R.), Policlinico Tor Vergata, Rome, Italy; Interventional Neuroradiology NEURI Center (V.D.R., J.C., A.R., C.M., L.I., J.M., L.S.), Hôpital Bicêtre, Le Kremlin Bicêtre, France; Department of Neurosurgery (C.M.), University of Medicine and Pharmacy "Victor Babes," Timisoara, Romania; and Université Paris-Sud XI (L.S.), Le Kremlin-Bicêtre, France.

Please address correspondence to Valerio Da Ros, Hôpital Bicêtre - Interventional Neuroradiology NEURI Center, 78 rue du Général Leclerc, 94270 Le Kremlin Bicêtre, France; e-mail: daros.valerio@gmail.com

三 Indicates article with supplemental on-line table.

http://dx.doi.org/10.3174/ajnr.A5167 ment of wide-neck, large aneurysms with promising clinical and angiographic outcomes. ${ }^{7-9}$ Only a few articles have reported the results of the use of flow-diverter stents in posterior circulation aneurysms, ${ }^{7,10,11}$ and concerns remain regarding their use.

Large BAAs are characterized by specific issues when a flowdiverter stent is the treatment of choice. These issues are mostly related to their anatomic location and include the risk of occlusion of the posterior cerebral (PCA) and superior cerebellar arteries, ${ }^{12}$ brain stem ischemic lesions caused by coverage of the perforator arteries, ${ }^{13}$ and delayed rupture of the treated aneurysm. ${ }^{14}$

The aim of this study was to report midterm follow-up results after the treatment of wide-neck, large BAAs with flow-diverter stents. We describe our experience in terms of the feasibility, safety, and efficacy of the procedure in this specific anatomic condition.

\section{MATERIALS AND METHODS}

From a prospective data base that collected data from all patients treated with a flow-diverter stent for intracranial aneurysms at our institution between January 2011 and January 2015, we searched for complex large BAAs. These were defined as aneu- 
rysms with a large diameter $(>10 \mathrm{~mm})$ and a wide neck treated with a flow-diverter stent either as the first-line treatment or after a recurrence after previous coiling.

As part of a multidisciplinary team, neurosurgeons and neuroradiologists discussed all the cases to determine the optimum aneurysm management. The individual risk-benefit analysis of different treatment modalities was taken into account, and a flowdiverter stent was chosen as the best treatment of choice after the exclusion of other endovascular (coiling, stent, or balloon-assisted coiling) or microsurgical (clip reconstruction or vessel sacrifice with or without bypass) approaches. Each decision was made in consensus with the patients and/or their relatives. Informed consent was obtained from all patients.

The periprocedural pharmacologic protocol for patients undergoing flow-diverter stent implantation was uniform throughout the study period. All patients were premedicated with a dualantiplatelet regimen (75 mg of clopidogrel with $160 \mathrm{mg}$ of aspirin per day) for at least 7 days before the procedure. Thrombocyte inhibition levels were confirmed by using the VerifyNow P2Y12 assay (Accumetrics, San Diego, California) and 4 hematologic laboratory tests. P2Y12 percent inhibition of 30\%-40\% was generally used as a minimum degree of preprocedure P2Y12 receptor inhibition required. All procedures were performed under heparinization, with a bolus of 2000-5000 IU of heparin administered once the femoral sheath was in place.

In all cases, the flow-diverter stent was delivered to cover the whole length of the aneurysm neck or remnant. The correct deployment was assessed with a VasoCT (Phillips Healthcare, Best, the Netherlands) scan, ${ }^{15}$ used to evaluate the necessity of further maneuver after stent deployment (ie, ballooning).

All patients underwent radiologic follow-up with conventional angiography, scheduled at 3-6, 12, and 24 months after treatment. MR imaging and MR angiography imaging were performed during the follow-up only where clinical symptoms changed.

For each patient, the following outcomes were evaluated: 1) the feasibility of the procedure, defined as the technical possibility of delivering the flow-diverter stent to the desired position; 2) the safety of the procedure, including early complications (defined as those occurring within 24-48 hours of the procedure) and late events (defined as events occurring during the follow-up period); 3) the efficacy in achieving target aneurysm occlusion, categorized by using the modified Raymond-Roy (mRR) classification ${ }^{16}$; adequate aneurysm occlusion (complete occlusion + neck remnant) considered as stable results during the subsequent follow-up was also assessed ${ }^{17}$; 4) major recurrence rates after flowdiverter stent deployment, defined as any increase in the size of the aneurysmal remnant that required retreatment during the follow-up period; and, 5) clinical outcome assessed by the mRS during midterm follow-up.

\section{RESULTS}

Between January 2011 and January 2015, 175 aneurysms were treated with flow-diverter stents at our institution. We identified 5 patients ( 3 men and 2 women) with wide-neck, large BAAs. Patient demographics and aneurysm characteristics are summarized in the On-line Table. Patient ages varied from 44-58 years, with a mean age of 50 years.
Aneurysm size ranged from $10-23 \mathrm{~mm}$, with a median value of $20 \mathrm{~mm}$. Of the 3 patients presenting with a ruptured aneurysm, 2 were treated with conventional coiling in the first instance, and 1 was treated with stent-assisted coiling (Patient 3).

The indications for flow-diverter stent implantation included: aneurysm recurrence after previous endovascular treatment with coils alone (Patients 4 and 5) or with stent and coils (Patient 3), intention-to-cure treatment with a single staged session of flowdiverter stent implantation after conventional coiling (Patient 2), or 2-step treatment with coils and a scheduled flow-diverter stent implantation within 6 weeks (Patient 1). Moreover, chiasmal compression syndrome was an additional indication for treatment in 1 patient (Patient 4).

The flow-diverter stents used were the Pipeline Embolization Device (Covidien, Irvine, California) in Patients 1 and 3, the Silk flow diverter (Balt Extrusion, Montmorency, France) in Patient 2, and the Flow-Redirection Endoluminal Device (FRED; MicroVention, Tustin, California) in Patients 4 and 5. The choice of the flow-diverter stent type was based on the operator's confidence with the device. Stent deployment was feasible without intraprocedural complications in all cases.

In all 5 cases, adequate occlusion of the BAAs was achieved at last follow-up (mean delay, 6 months) without any major recurrence after flow-diverter stent implantation.

PCAs and superior cerebellar arteries covered by the flow diverter were patent during the follow-up for Patients 1, 2, 3, and 4. In Patient 5, both covered superior cerebellar arteries were not visualized at the subsequent DSA follow-up (Fig 1). This patient presented with a postprocedural transient cerebellar syndrome caused by a small infarction of the right cerebellar hemisphere that resolved within 24 hours, without associated neurologic sequelae during the follow-up; in Patient 2, a fatal postprocedural hemorrhage occurred 12 hours after flow-diverter stent deployment. The 3 remaining patients did not present with changes to their clinical symptoms during the follow-up period. Patient 4 , who presented with an amputation of the visual field, with "tunnel vision" caused by chiasmal compression, completely recovered visual acuity within 6 months of flow-diverter stent implantation.

Here, we report a brief description of each case.

\section{Illustrative Cases}

Patient 1. A 44-year-old man underwent an MR imaging evaluation for acute severe headache, which identified an incidental, large, wide-neck, nonthrombosed BAA.

On 3D-DSA, the BAA measured $20 \times 18 \times 12 \mathrm{~mm}$ (Fig 2).

The aneurysm was first treated with a simple coiling with loose packing attenuation; the treatment was completed 6 weeks later, with the deployment of a $3.5 \times 20 \mathrm{~mm}$ Pipeline flow-diverter stent. The latest DSA follow-up ( 24 months) revealed complete aneurysmal occlusion (mRR class I; mRS, 0).

Patient 2. A 58-year-old woman presented with a progressive midbrain compression syndrome caused by a large BAA discovered on MR imaging.

The $3 \mathrm{D}$-DSA showed a $23 \times 21 \mathrm{~mm}$ wide-neck, large BAA

AJNR Am J Neuroradiol 38:1156-62 Jun 2017 www.ajnr.org 1157 


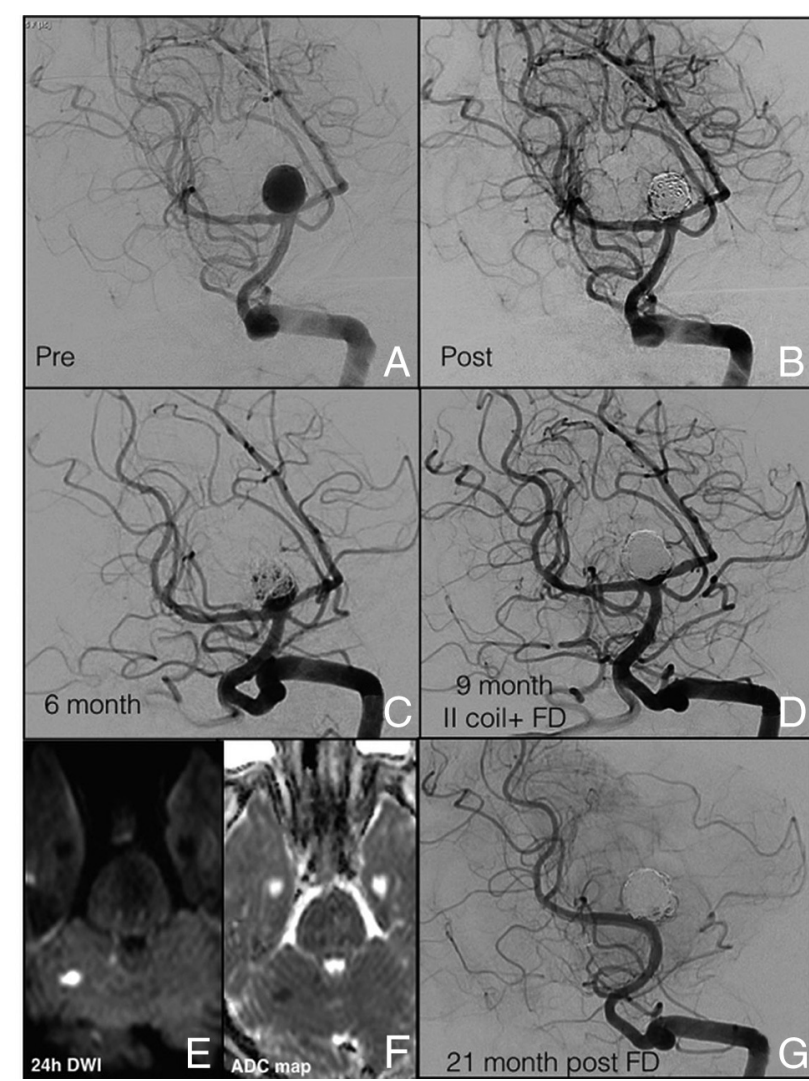

FIG 1. A, DSA shows a ruptured large BAA $(10 \times 10 \mathrm{~mm}$; neck, $4.4 \mathrm{~mm})$. $B$, Aneurysmal embolization was performed with the balloon-remodeling technique. C, Six-month DSA follow-up shows a significant neck recanalization $(5 \mathrm{~mm} \times 6 \mathrm{~mm})$. $D$, At the 9-month follow-up, a second coiling remodeling technique associated with the deployment of a FRED flow-diverter stent across the right PCA was performed. $E$ and $F$, The 24-hour postprocedural MR imaging, with DWI and ADC map, shows the presence of a small ischemic right cerebellar lesion. G, At 21-month DSA follow-up, both covered superior cerebellar arteries were not visualized, and the persistence of complete BAA occlusion was confirmed (mRR class I; mRS, 0).

treated in a single session with coiling and a Silk flow-diverter stent (Fig 3).

Twelve hours after the treatment, the patient experienced an acute loss of consciousness. The MR imaging showed a midbrain hematoma associated with an intraventricular hemorrhage and an acute hydrocephalus. Steroids were administered to reduce the midbrain posthemorrhagic edema, and a second flowdiverter stent was deployed; then, an external ventricular shunt was inserted.

After 5 days, the patient, already under mechanical ventilation, experienced fever and severe pneumonia. The 2 -week DSA and MR imaging follow-up demonstrated aneurysmal sac occlusion (mRR class I) and mild increase of the initial hydrocephalus.

After the recurrence of a second episode of hypoxic pneumonia, the patient died on day 31 of hospitalization (mRS, 6).

Patient 3. A 45-year-old man presented with an acute SAH and a Glasgow Coma Scale score of 13. The initial DSA showed a wide-neck BAA $(8 \times 10 \mathrm{~mm})$, which was embolized with a stent-assisted (Neuroform; Stryker Neurovascular, Kalamazoo, Michigan [3.5 $\mathrm{mm} \times 20 \mathrm{~mm}$ ]) coiling technique (Fig 4).

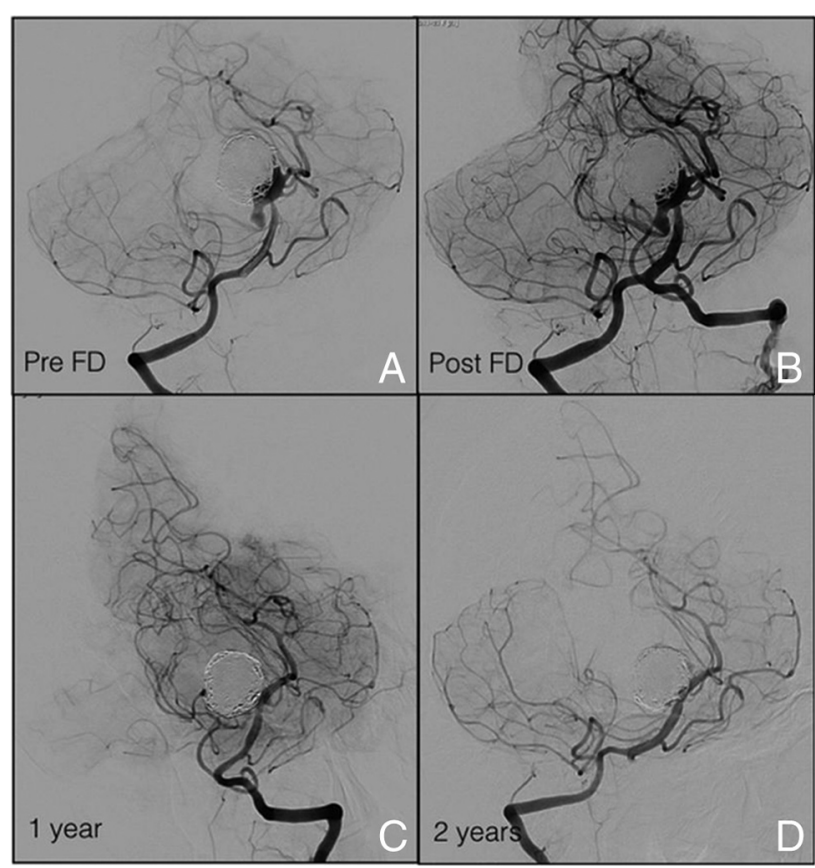

FIG 2. A, DSA shows the remnant of a wide-neck, large BAA aneurysm that involved both superior cerebellar arteries and the left Pl segment, with a 5-mm right superior cerebellar artery fusiform aneurysm, and a fetal origin of the right PCA, treated with a simple coiling. B, Six weeks later, the remnant was treated with a Pipeline stent. C, Twelvemonth and D, 24-month follow-up DSA reveal complete aneurysmal occlusion (mRR class I).

At 15-month follow-up, DSA revealed a residual aneurysmal neck, which appeared enlarged on the subsequent DSA follow-up 4 months later $(8 \mathrm{~mm} \times 5 \mathrm{~mm} \times 2 \mathrm{~mm})$. A Pipeline flow-diverter stent was used to treat the neck remnant. The 15-month DSA showed adequate sac occlusion (mRR class IIIa; mRS, 0).

Patient 4. A 53-year-old man had a recent history of a large (20 $\mathrm{mm}$ ), wide-neck, ruptured BAA that had been partially coiled at another institution. Four months later, an increased aneurysmal mass effect on the chiasma was seen on MR imaging. At that time, the patient presented with an amputation of the visual field with "tunnel vision," and a second partial coiling embolization was performed (Fig 5). After a 3-month early aneurysmal recurrence $(10 \mathrm{~mm} \times 9 \mathrm{~mm})$, an additional coiling of the sac remnant and flow-diverter stent deployment (FRED $3.5 \mathrm{~mm} \times 16-22 \mathrm{~mm}$ ) was performed.

The 24-month DSA follow-up showed adequate BAA occlusion ( $\mathrm{mRR}$ class IIIa), along with complete recovery of the visual field (mRS, 0).

Patient 5. A 46-year-old woman was referred to the emergency department with an acute SAH (classified as Fisher 4 with hydrocephalus; Glasgow Coma Scale, 12) caused by a ruptured BAA $(10 \times 10 \mathrm{~mm}$; neck, $4.4 \mathrm{~mm})$. The aneurysm was coiled, and at the 6-month DSA follow-up, a neck recanalization $(5 \mathrm{~mm} \times 6 \mathrm{~mm})$ was observed (Fig 1).

At 9-month follow-up, a second coiling was performed, along with a FRED flow-diverter stent deployment.

Upon waking from anesthesia, the patient presented with a 


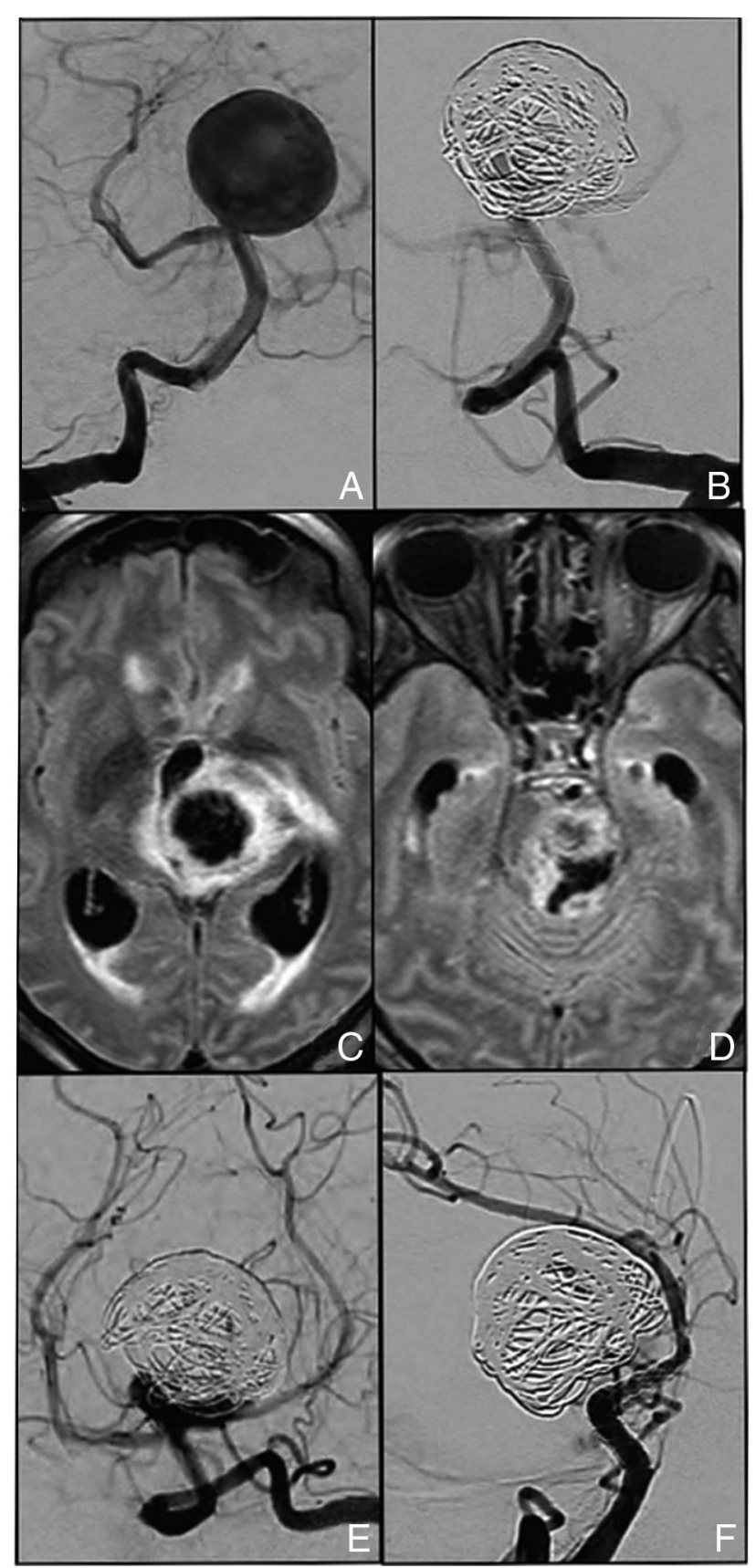

FIG 3. $A, D S A$ shows a wide-neck, large BAA aneurysm $(B)$ treated in a single session with coiling and a Silk flow-diverter stent across the left PCA. $C$ and D, MR imaging shows the presence of a midbrain hematoma 12 hours after the treatment. E. Anteroposterior view DSA shows residual filling at the level of the aneurysmal neck. A second Pipeline flow diverter was then deployed. $F$, The 2-week DSA follow-up shows complete aneurysmal sac occlusion (mRR class I).

cerebellar kinetic syndrome with diplopia, confirmed by the presence of a small ischemic right cerebellar lesion on the postprocedural MR imaging; the neurologic symptoms completely resolved within 24 hours.

The patient was maintained on a full dose of heparin and an elevated arterial pressure (mean, $140 \mathrm{~mm} \mathrm{Hg}$ ) for 1 week.

At 21-month DSA follow-up, both covered superior cerebellar arteries were not visualized, and the persistence of complete BAA occlusion was confirmed (mRR class I; mRS, 0 ).

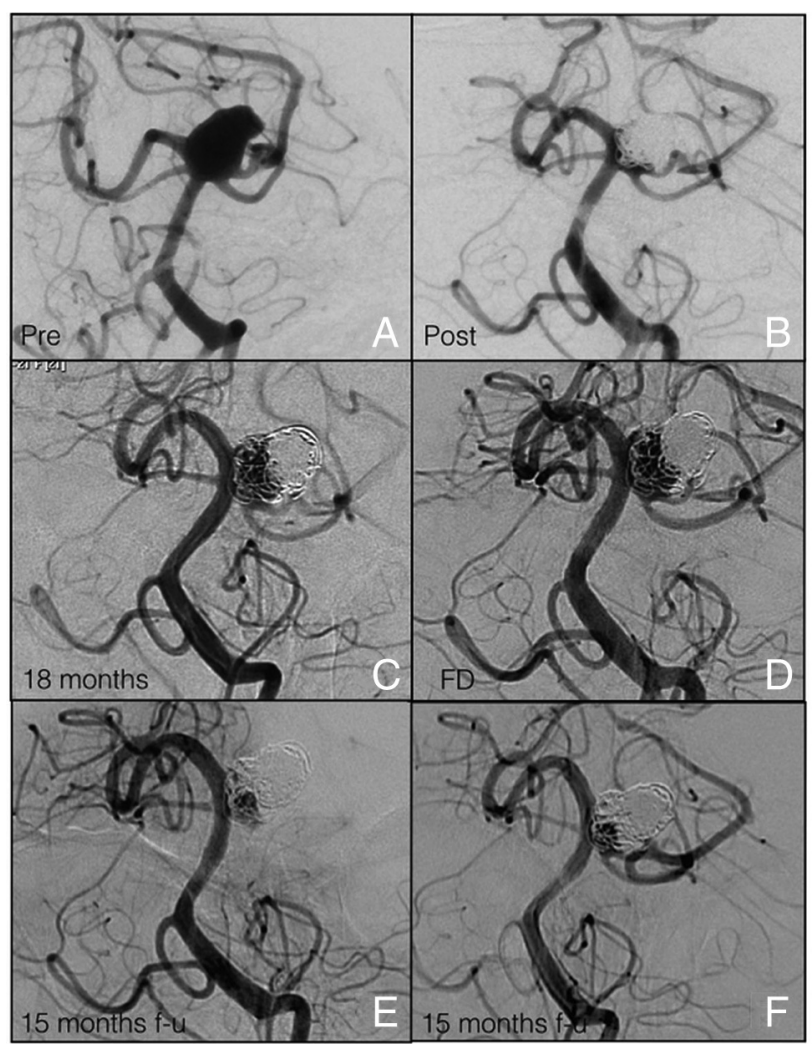

FIG 4. A, The initial DSA demonstrates a wide-neck, large BAA involving the origin of both PCAs and superior cerebellar arteries $(B)$ treated with a stent-assisted coiling technique (Neuroform $3.5 \mathrm{~mm} \times 20 \mathrm{~mm}$ ). $C$, The 18-month DSA follow-up reveals an aneurysmal recurrence at the level of the neck. $D$, A Pipeline stent was used to treat the neck remnant with $(E)$ adequate aneurysm occlusion at 15-month DSA follow-up (mRR class IIIa) demonstrated in the working projection. $F$, The compression test performed confirms the result.

\section{DISCUSSION}

Of the few articles reporting the treatment of posterior circulation aneurysms with flow-diverter stents, ${ }^{7,10,11}$ to the best of our knowledge, none have focused on the use of flow-diverter stents for the treatment of wide-neck, large BAAs. In this clinical report, we describe the remarkable midterm follow-up results we obtained with the use of flow-diverter stents in this infrequent location. We detailed the feasibility and efficacy of the technique, including its ability to determine aneurysmal growth arrest in all the cases of aneurysmal recurrence after previous endovascular treatments.

Use of flow diverters in the posterior circulation carries higher complication rates compared with use in the anterior circulation. However, in the literature, flow diverters in the posterior circulation were mostly used for the treatment of dissecting, fusiform, and/or partially thrombosed aneurysms ${ }^{18}$; this makes the comparison of our findings with previous series difficult.

In this study, flow-diverter stent deployment was feasible in all patients, and compared with surgical clipping, the flow-diverter stent deployment presented a less technical challenge. ${ }^{19}$ The fact that all treated patients in this series except 1 (Patient 2) had wide-neck, large BAA recurrences after previous endovascular treatments (ie, coiling or stent + coiling) was the determinant for us to adopt a different strategy concept: flow diversion. In all cases 


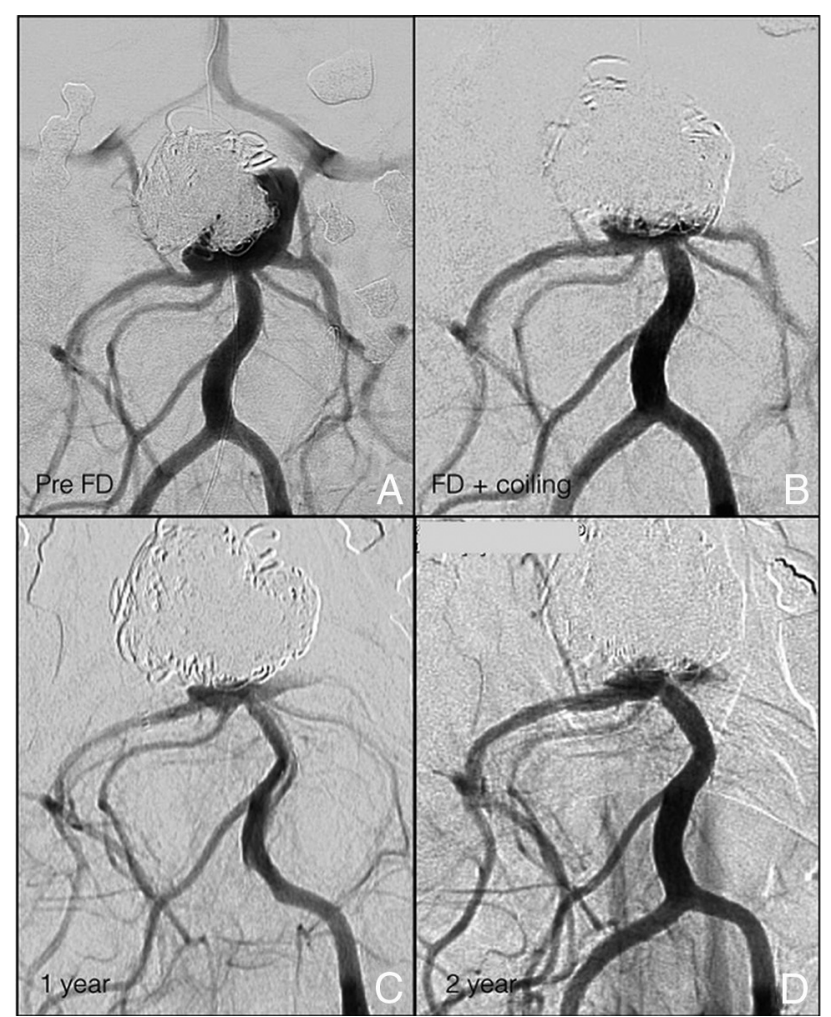

FIG 5. A, The preoperative DSA shows a large, wide-neck BAA, twice partially coiled in an emergency setting, responsible for a chiasmal compression syndrome. $B$, Additional coiling of the sac remnant occurred and a subsequent flow-diverter stent (FRED $3.5 \mathrm{~mm} \times 22-16$ $\mathrm{mm}$ ) was deployed across the right $\mathrm{Pl}$ segment. $C$, Twelve-month and $D$, 24-month DSA follow-up demonstrate adequate BAA occlusion (mRR class IIIa), and the visual field was completely recovered.

of BAA recurrence (Patients 1, 3, 4, and 5), the flow-diverter stent was intended as a "rescue" strategy where a coiling procedure had failed. The flow-diverter deployment determined progressive sac exclusion, with no need for further treatments during follow-up.

Although other treatment options were available, the use of a flow-diverter stent offered a more effective scaffolding to the diseased target artery compared with a conventional stent; moreover, other techniques such as Y-stent placement have demonstrated efficacy in previous studies. However, according to Bartolini et al, ${ }^{20}$ Y-stent placement carries the risk of up to $10 \%$ procedure-related permanent neurologic deficits. Finally, the flow-diverter stent deployment was a less technically demanding procedure than the Y-stent placement technique.

Patient 2 was treated for an unruptured BAA with coiling and flow-diverter stent in a single session, with a "first intention-tocure" strategy, and the patient experienced an early postprocedural hemorrhage.

The delayed aneurysm rupture risk after flow-diverter stent deployment has been previously described. ${ }^{14}$ The small population of this study determines the impossibility of relating the only hemorrhagic complication observed to a specific type of device rather than to the flow-diversion effect. However, the rapid intraaneurysmal thrombus formation is a source of various proteases with high proteolytic activity, which could participate in the degradation of the arterial wall and lead to aneurysm rupture. Moreover, the larger aneurysms, like those presented in this series, are generally more likely to have intraluminal thrombus. ${ }^{21-23}$ Thus, this mechanism probably was the most involved in the delayed aneurysm rupture observed in Patient 2. In this case, the steroids were administered only after aneurysmal rupture, mainly to reduce the midbrain posthemorrhagic edema because, to the best of our knowledge, the efficiency of steroids to prevent the lytic activity has not been demonstrated yet. ${ }^{24}$ Unfortunately, how to prevent this dramatic complication is still a matter of debate.

To protect against delayed aneurysm rupture, ${ }^{25}$ our choice was the use of loose-packing coiling before flow-diverter stent. Retrospectively, we assume that the loose-packing coiling was not sufficient to act as a scaffold to organize thrombi into stable fibrous tissue $e^{26}$ and that the time between the procedures was not long enough to allow a progressive thrombus formation after coiling. Our experience confirms that the optimum packing attenuation of coils and the timing between coiling and flow-diverter stent placement is still to be determined.

Posterior circulation flow-diverter stents carry a risk of ischemic lesions caused by the occlusion of covered branches (ie, superior cerebellar arteries and PCAs), ${ }^{27}$ including a higher rate of injury to posterior perforators relative to their anterior counterparts. ${ }^{3,28,29}$

In this series, we observed 1 case (Patient 5) of early ischemic lesion after flow-diverter stent coverage. In this case, the placement of a flow diverter in front of the superior cerebellar arteries led to their early occlusion, with a unilateral transient cerebellar syndrome observed after the procedure. At the subsequent follow-up, the superior cerebellar artery occlusion remained clinically silent. To the best of our knowledge, there is no previous literature specifically analyzing superior cerebellar artery occlusion after flow-diverter coverage. However, in the anterior circulation, slow flow of the side branches covered by the flow-diverter stent is observed in up to $19.1 \%$ of cases $^{30}$ and vessel occlusion is observed in up to $21 \% .{ }^{31}$ In most of these cases, neither permanent deficit or death nor neurologic deficit were described within covered branches, perhaps because of the good collateral circulation. ${ }^{11,27,30}$ As described by Alqadri et al, ${ }^{32}$ several collateral anastomoses also exist in the posterior circulation. These findings suggest that in Patient 5, the occlusion of the superior cerebellar arteries after flow-diverter stent deployment was responsible for an initial vascular and hemodynamic regional unbalance, which determined an early initial clinical manifestation. The subsequent early activation of the posterior collateral circulation allowed for the patient's rapid clinical improvement without neurologic manifestation during the follow-up. In case of uncertainty regarding the collateral circulation, it could be valuable to perform a balloon occlusion test to assess the vascular territory supply of the covered branches.

Finally, deploying flow-diverter stents in the basilar bifurcation determines flow modification at the level of the covered PCA.

In accordance with the anatomic knowledge of Brassier et $\mathrm{al}^{33}$ to protect as many perforators as possible, the flow diverter should reasonably be deployed in the most caudal PCA, where the number of perforators is less common. However, it also should be taken into account that most of the flow diverters are composed of microfilaments of $30-35 \mu \mathrm{m}$, and the pore size varies between $110-250 \mu \mathrm{m}$ (much depending on the final FD mor- 
phology and selection of the proper size adapted to the vessel diameter). ${ }^{34}$ These anatomic characteristics suggest that in the worst case, when 2 filaments cross in front of a $100 \mu \mathrm{m}$ perforator vessel, this small artery will lose no more than $55 \%$ of its orifice area. This still provides sufficient blood flow to the distribution territory. ${ }^{35}$

Thus, to choose which PCA to put the stent in, we mostly focused our attention on hemodynamic criteria. In particular, we simply decided to cover the smallest P1 segment with the largest posterior communicating artery with the stent. This approach was based on several reasons. First, in case of subsequent occlusion of the covered P1 segment, this would be supplied by a larger posterior communicating artery. Second, in this configuration, the larger uncovered posterior communicating artery is preferentially used to supply the distal P2 segment in an anterograde fashion (rather than the $\mathrm{P} 1$ segment in a retrograde fashion). As a consequence, the filling flow into the aneurysmal sac from the covered P1 is potentially reduced. Finally, a flow diverter deployed in the P1 segment with the smaller or absent posterior communicating artery determines a higher gradient pressure at that level because of the reduced flow competition between the P1 segment and posterior communicating artery. This theoretically favors the perforators' patency maintenance.

In line with these considerations, in Patients 1, 2, and 3, this approach induced flow changes in the smaller covered posterior communicating artery, with posterior communicating arteries still patent, but no more visible except after performing an occlusion test (Patient 3); in Patient 4, we decided to put the flowdiverter stent in the right PCA because the right posterior communicating artery was smaller compared with the left one; finally, in Patient 5, we decided to deploy the stent in the right PCA only because it was technically easier because neither anatomic nor hemodynamic differences were observed between the right and left side (with a symmetry of both PCAs and posterior communicating arteries and the aneurysmal neck centered between the 2 PCAs). This approach has proved to be efficient in preserving covered PCA patency without significant aneurysm sac supply at midterm follow-up and with no perforator infarction observed.

\section{Limitations}

This clinical report has several limitations, including the small number of patients and the retrospective collection of the cases. However, all the wide-neck, large BAAs treated with flow-diverter stents in our department have been included in this series without any selection. In addition, the follow-up period is quite short; longer follow-up is essential to assess the long-term stability of adequate occlusion. Because of the small size of this study, we did not perform between-case analysis.

\section{CONCLUSIONS}

A wide-neck, large BAA is a complex, multifactorial problem, for which the use of flow-diverter stents plus coiling appears to be a promising approach. However, the exact staging of the treatments and the packing density of coiling require further evaluation to minimize the risk of its application.
Disclosures: Jacques Moret-UNRELATED: Consultancy: Microvention-StrykerMedtronic. Laurent Spelle-UNRELATED: Consultancy: Stryker, Medtronic, Sequent.

\section{REFERENCES}

1. Brisman JL, Song JK, Newell DW. Cerebral aneurysms. N Engl J Med 2006;355:928-39 CrossRef Medline

2. Vallee JN, Aymard A, Vicaut E, et al. Endovascular treatment of basilar tip aneurysms with Guglielmi detachable coils: predictors of immediate and long-term results with multivariate analysis 6-year experience. Radiology 2003;226:867-79 CrossRef Medline

3. Wong GK, Kwan MC, Ng RY, et al. Flow diverters for treatment of intracranial aneurysms: current status and ongoing clinical trials. J Clin Neurosci 2011;18:737-40 CrossRef Medline

4. Taki W, Sakai N, Nakahara I, et al. Circulatory arrest with profound hypothermia during the surgical treatment of large internal carotid artery aneurysm-case report. Neurol Med Chir (Tokyo) 1998;38: 725-29 CrossRef Medline

5. Sekhar LN, Tariq F, Morton RP, et al. Basilar tip aneurysms: a microsurgical and endovascular contemporary series of 100 patients. Neurosurgery 2013;72:284-98; discussion 298-99 CrossRef Medline

6. Jin SC, Ahn JS, Kwun BD, et al. Analysis of clinical and radiological outcomes in microsurgical and endovascular treatment of basilar apex aneurysms. J Korean Neurosurg Soc 2009;45:224-30 CrossRef Medline

7. Lylyk P, Miranda C, Ceratto R, et al. Curative endovascular reconstruction of cerebral aneurysms with the Pipeline embolization device: the Buenos Aires experience. Neurosurgery 2009;64:632-42; discussion 642-43; quiz N6 CrossRef Medline

8. Lubicz B, Collignon L, Raphaeli G, et al. Flow-diverter stent for the endovascular treatment of intracranial aneurysms: a prospective study in 29 patients with 34 aneurysms. Stroke 2010;41:2247-53 CrossRef Medline

9. Becske T, Kallmes DF, Saatci I, et al. Pipeline for uncoilable or failed aneurysms: results from a multicenter clinical trial. Radiology 2013; 267:858-68 CrossRef Medline

10. Fiorella D, Kelly ME, Albuquerque FC, et al. Curative reconstruction of a giant midbasilar trunk aneurysm with the Pipeline embolization device. Neurosurgery 2009;64:212-17; discussion 217 CrossRef Medline

11. Szikora I, Berentei Z, Kulcsar Z, et al. Treatment of intracranial aneurysms by functional reconstruction of the parent artery: the Budapest experience with the Pipeline embolization device. AJNR Am J Neuroradiol 2010;31:1139-47 CrossRef Medline

12. Kan P, Duckworth E, Puri A, et al. Treatment failure of fetal posterior communicating artery aneurysms with the Pipeline embolization device. J Neurointerv Surg 2016;8:945-48 CrossRef Medline

13. Kulcsár Z, Ernemann U, Wetzel SG, et al. High-profile flow diverter (Silk) implantation in the basilar artery: efficacy in the treatment of aneurysms and the role of the perforators. Stroke 2010;41:1690-96 CrossRef Medline

14. Rouchaud A, Brinjikji W, Lanzino G, et al. Delayed hemorrhagic complications after flow diversion for intracranial aneurysms: a literature overview. Neuroradiology 2016;58:171-77 CrossRef Medline

15. Caroff J, Mihalea C, Neki H, et al. Role of C-arm VasoCT in the use of endovascular WEB flow disruption in intracranial aneurysm treatment. AJNR Am J Neuroradiol 2014;35:1353-57 CrossRef Medline

16. Mascitelli JR, Moyle H, Oermann EK, et al. An update to the Raymond-Roy Occlusion Classification of intracranial aneurysms treated with coil embolization. J Neurointerv Surg 2015;7:496-502 CrossRef Medline

17. Lubicz B, Van der Elst O, Collignon L, et al. Silk flow-diverter stent for the treatment of intracranial aneurysms: a series of 58 patients with emphasis on long-term results. AJNR Am J Neuroradiol 2015; 36:542-46 CrossRef Medline

18. Wang CB, Shi WW, Zhang GX, et al. Flow diverter treatment of posterior circulation aneurysms. A meta-analysis. Neuroradiology 2016;58:391-400 CrossRef Medline

AJNR Am J Neuroradiol 38:1156-62 Jun 2017 www.ajnr.org 
19. Spetzler RF, Hadley MN, Rigamonti D, et al. Aneurysms of the basilar artery treated with circulatory arrest, hypothermia, and barbiturate cerebral protection. J Neurosurg 1988;68:868-79 CrossRef Medline

20. Bartolini B, Blanc R, Pistocchi S, et al. " $Y$ " and "X" stent-assisted coiling of complex and wide-neck intracranial bifurcation aneurysms. AJNR Am J Neuroradiol 2014;35:2153-58 CrossRef Medline

21. Turowski B, Macht S, Kulcsár Z, et al. Early fatal hemorrhage after endovascular cerebral aneurysm treatment with a flow diverter (SILK-stent): do we need to rethink our concepts? Neuroradiology 2011;53:37-41 CrossRef Medline

22. Berge J, Biondi A, Machi P, et al. Flow-diverter Silk stent for the treatment of intracranial aneurysms: 1-year follow-up in a multicenter study. AJNR Am J Neuroradiol 2012;33:1150-55 CrossRef Medline

23. Velioglu M, Kizilkilic O, Selcuk $\mathrm{H}$, et al. Early and midterm results of complex cerebral aneurysms treated with Silk stent. Neuroradiology 2012;54:1355-65 CrossRef Medline

24. Thielen E, McClure M, Rouchaud A, et al. Concomitant coiling reduces metalloproteinase levels in flow diverter-treated aneurysms but anti-inflammatory treatment has no effect. J Neurointerv Surg 2017;9:307-10 CrossRef Medline

25. Cebral JR, Mut F, Raschi M, et al. Aneurysm rupture following treatment with flow-diverting stents: computational hemodynamics analysis of treatment. AJNR Am J Neuroradiol 2011;32:27-33 CrossRef Medline

26. Natarajan SK, Lin N, Sonig A, et al. The safety of Pipeline flow diversion in fusiform vertebrobasilar aneurysms: a consecutive case series with longer-term follow-up from a single US center. J Neurosurg 2016;125:111-19 CrossRef Medline

27. Brinjikji W, Lanzino G, Cloft HJ, et al. Patency of the posterior com- municating artery after flow diversion treatment of internal carotid artery aneurysms. Clin Neurol Neurosurg 2014;120:84-88 CrossRef Medline

28. Marinković SV, Gibo H. The surgical anatomy of the perforating branches of the basilar artery. Neurosurgery 1993;33:80-87 CrossRef Medline

29. Marinković S, Milisavljević M, Kovacević M. Interpeduncular perforating branches of the posterior cerebral artery. Microsurgical anatomy of their extracerebral and intracerebral segments. Surg Neurol 1986;26:349-59 CrossRef Medline

30. Gascou G, Lobotesis K, Brunel H, et al. Extra-aneurysmal flow modification following Pipeline embolization device implantation: focus on regional branches, perforators, and the parent vessel. AJNR Am J Neuroradiol 2015;36:725-31 CrossRef Medline

31. Puffer RC, Kallmes DF, Cloft HJ, et al. Patency of the ophthalmic artery after flow diversion treatment of paraclinoid aneurysms. J Neurosurg 2012;116:892-96 CrossRef Medline

32. Alqadri S, Adil MM, Watanabe M, et al. Patterns of collateral formation in basilar artery steno-occlusive diseases. J Vasc Interv Neurol 2013;6:9-13 Medline

33. Brassier G, Morandi X, Fournier D, et al. Origin of the perforating arteries of the interpeduncular fossa in relation to the termination of the basilar artery. Interv Neuroradiol 1998;4:109-20 CrossRef Medline

34. Shapiro M, Raz E, Becske T, et al. Variable porosity of the Pipeline embolization device in straight and curved vessels: a guide for optimal deployment strategy. AJNR Am J Neuroradiol 2014;35:727-33 CrossRef Medline

35. Seong J, Wakhloo AK, Lieber BB. In vitro evaluation of flow divertors in an elastase-induced saccular aneurysm model in rabbit. J Biomech Eng 2007;129:863-72 CrossRef Medline 